\title{
Anticancer Effects of Colchicine on Hypopharyngeal Cancer
}

\author{
JUNG HAE CHO ${ }^{1}$, YOUNG HOON JOO ${ }^{1}$, EUN YOUNG SHIN ${ }^{2}$, EUN JI PARK ${ }^{1}$ and MIN SIK KIM ${ }^{1}$ \\ ${ }^{1}$ Department of Otolaryngology-Head and Neck Surgery, College of Medicine, \\ The Catholic University of Korea, Seoul, Republic of Korea; \\ ${ }^{2}$ Research Institute of Medical Science, St. Vincent's Hospital, \\ The Catholic University of Korea, Seoul, Republic of Korea
}

\begin{abstract}
Colchicine is an alkaloid widely used for the treatment of inflammatory diseases, such as gout. It suppresses cell division by inhibiting mitosis. We investigated the anticancer effects of colchicine on human hypopharyngeal cancer cells and the mechanisms underlying its anticancer effects. XTT cell proliferation assay showed that colchicine inhibited the growth and proliferation of human hypopharyngeal cancer cells (FaDu and SNU1041) in a doseand time-dependent manner. Colchicine also inhibited the migration, invasion, and adhesion of hypopharyngeal cancer cells in a dose-dependent manner. The levels of mRNA expression and activity of matrix metalloproteinase-9 (MMP9) and urokinase-type plasminogen activator (uPA) decreased after treatment with colchicine. Further investigation revealed that colchicine inhibited the phosphorylation of the FAK/SRC complex and paxillin. Tumor volume ratios in colchicine-treated mice $(0.1 \mathrm{mg} / \mathrm{kg}$, every 2 days for 14 days) increased less than in control mice. To our knowledge, this is the first report showing that colchicine can suppress cell invasion, migration, and adhesion through reduced expression of $M M P 9$, the $U P A$ system, and the FAK/SRC complex. Colchicine has the potential to prevent disease progression in hypopharyngeal cancer and may have application as an adjunctive treatment.
\end{abstract}

Hypopharyngeal cancer has the worst 5-year survival rate (overall estimated rate of $30-40 \%$ ) among all primary cancers of the head and neck (1). Nearly all hypopharyngeal carcinomas are squamous cell carcinomas, that are known to have a high metastatic potential. Most head and neck

Correspondence to: Professor Min-Sik Kim, MD, Ph.D., Department of Otolaryngology Head and Neck Surgery, Seoul St. Mary's Hospital, College of Medicine, The Catholic University of Korea, 222 Banpo-daero, Seocho-gu, Seoul, 06591, Republic of Korea. Tel: +82 222586212, e-mail: entkms@catholic.ac.kr

Key Words: Colchicine, hypopharyngeal cancer, invasion, metastasis. cancer-related deaths are due to local invasion of vital organs and the development of distant metastases. Patients with distant metastases of hypopharyngeal cancer have a mortality rate of more than $90 \%$. Despite recent advances in surgery and chemoradiotherapy, the overall survival rate has not changed for hypopharyngeal cancer. Therefore, new modalities for treatment are needed to prevent metastasis and improve the survival rate.

Microtubules have long been considered an ideal target for anticancer drugs because of their essential roles in mitosis and formation of the dynamic spindle apparatus (2). Colchicine is a natural pharmaceutical alkaloid derived from the seeds and tubers of Gloriosa superba (3). It can lead to microtubule depolymerization through formation of a stable complex with unpolymerized tubulin heterodimers (4), and has been widely used as an immunosuppressant, for the treatment of gout, and during kidney transplantation; however, it has not been used clinically to treat cancer. Because the availability of tubulin is essential for mitosis, colchicine can effectively function as a mitotic poison. Understanding the anticancer mechanism of colchicine may lead to new clinical applications in cancer treatment. Therefore, we investigated the anticancer effects of colchicine on hypopharyngeal cancer cell lines. We also examined the molecular mechanism of colchicine inhibition on cell adhesion, migration, and invasion. Finally, we extended our study to determine the effects of colchicine in a nude mouse model of hypopharyngeal cancer.

\section{Materials and Methods}

Cell lines and reagents. Two established human hypopharyngeal cancer cell lines, FaDu and SNU1041 (squamous cell carcinoma lines), were used. FaDu was kindly provided by Professor Chul-Ho Kim (Ajou University, School of Medicine, Suwon, South Korea) and SNU1041 was obtained from the Korean Cell Line Bank (Seoul, South Korea). $\mathrm{FaDu}$ was grown in minimum essential medium (MEM; Gibco, Carlsbad, CA, USA), while SNU 1041 was maintained in RPMI-1640 medium (Gibco). The cells were maintained at $37^{\circ} \mathrm{C}$ with $5 \% \mathrm{CO}_{2}$ under humidified conditions. Colchicine was purchased from 
Sigma-Aldrich Co. (St. Louis, MO, USA) and dissolved in autoclaved water as a stock solution for in vitro studies.

Cell proliferation assay. Cell proliferation was determined by XTT assay, using the Cell Proliferation Kit II (Roche Molecular Biochemicals, Germany). Hypopharyngeal cancer cells (FaDu and SNU1041) were seeded in 96 -well plates at $1 \times 104 / \mathrm{ml}$ after pretreatment with $0,0.01,0.1$, or $1 \mu \mathrm{M}$ of colchicine for 24,48 , or $72 \mathrm{~h}$. Cell viability was assessed by incubating cells with $0.5 \mathrm{mg} / \mathrm{ml} \mathrm{XTT}$ for $4 \mathrm{~h}$. The XTT-formazan produced by viable cells was then dissolved in dimethyl sulfoxide (DMSO). The optical density (OD) values were determined by spectrophotometry at $570-630 \mathrm{~nm}$ using an ELx 800 Microplate Reader (Bio-Tec Instruments Inc., Winooski, VT, USA). The OD values represent the relative numbers of viable cells.

Flow cytometric detection of apoptosis. Apoptosis was detected using an annexin V-fluorescein isothiocynate (FITC) apoptosis detection kit (ApoScan Kit; BioBud, Gyunggi-do, South Korea). $\mathrm{FaDu}$ cells were plated in 6-well culture dishes and incubated with $0,0.01,0.1$, or $1 \mu \mathrm{M}$ colchicine for $24 \mathrm{~h}$. Cells were harvested, washed with PBS, and stained with annexin V-FITC and propidium iodide (PI). Early and late apoptosis were quantified according to the manufacturer's instructions. Apoptosis was detected using a fluorescence-activated cell sorting (FACS) Canto system (BD Biosciences, Bedford, MA, USA), with excitation and emission settings of 488 and $635 \mathrm{~nm}$, respectively.

Wound-healing assay. FaDu cells were plated in culture plates at a density of approximately $1 \times 10^{5} /$ well in the presence of serum and grown to confluency. The monolayer was then scratched using a $200 \mu \mathrm{l}$ micropipette tip, followed by extensive washing with PBS to remove floating cellular debris. Serum-containing medium without or with increasing concentrations of colchicine $(0,1,10$, and $100 \mathrm{nM})$, was added to the cultures and the cells were further incubated. The distance migrated by the cells was measured and quantified over two time periods ( 24 and $48 \mathrm{~h}$ ) by observation under a light microscope. Representative fields were photographed.

Cell migration and invasion assay (Transwell). Cell migration was assayed in Transwell (24-well) chambers (Costar, Cambridge, MA, USA) according to the method of Ho et al. with some modifications (5). We used Transwell chambers with $6.5 \mathrm{~mm}$ polyvinyl/ pyrrolidone-free polycarbonate filters and an $8 \mu \mathrm{m}$ pore size. $\mathrm{FaDu}$ cells $\left(5 \times 10^{5} / \mathrm{ml}\right)$ and colchicine $(0,1,10,100 \mathrm{nM})$ were suspended in $100 \mu \mathrm{l}$ of serum-free Dulbecco's modified Eagle's medium (DMEM) before being placed in the upper transwell chamber; for the lower chamber, $10 \%$ fetal bovine serum (FBS)-containing medium was added as a chemoattractant. After $24 \mathrm{~h}$ of incubation at $37^{\circ} \mathrm{C}$, cells on the upper surface of the filter were completely wiped off with a cotton swab and the lower surface of the filter was fixed in methanol, stained with hematoxylin, and cells counted under a microscope at a magnification of $\times 100$. For each replicate, the number of tumor cells in 10 randomly selected fields was counted and the counts were averaged.

The invasion of tumor cells was also assessed using Transwell chambers with $6.5 \mathrm{~mm}$ polycarbonate filters and an $8 \mu \mathrm{m}$ pore size, as described for the cell migration assay, except that each filter was coated with $100 \mu \mathrm{l}$ of collagen IV (1:20 dilution in cold DMEM) to form a thin, continuous film on the top of the filter. Cells were adjusted to a density of $5 \times 10^{5} / \mathrm{ml}$ and $100 \mu$ (containing $5 \times 10^{4}$ cells) in DMEM containing 10\% FBS were transferred to each well, repeated in triplicate. After incubating for $24 \mathrm{~h}$, the cells were stained and the number of cells invading the lower side was counted.

Cell adhesion assay. Adhesion was measured using the CytoSelect ${ }^{\mathrm{TM}}$ Cell Adhesion Assay kit (Cell Biolabs, San Diego, CA, USA) according to the manufacturer's instructions. After overnight incubation, colchicine $(0,0.01,0.1,1 \mu \mathrm{M})$ was added to the wells and the plates were incubated for a further $24 \mathrm{~h}$. Cells were harvested and re-suspended in serum-free DMEM/F-12 medium. Four collagen IVcoated wells, and one bovine serum albumin-coated well were used; $5 \times 10^{5}$ cells were added to each well in a volume of $150 \mu \mathrm{l}$. One collagen IV-coated well was treated with sterile serum-free DMEM/F12 as a negative control. The plate was then incubated at $37^{\circ} \mathrm{C}, 5 \% \mathrm{CO}_{2}$ for $90 \mathrm{~min}$. The cells were then washed four times with $250 \mu \mathrm{l}$ of PBS and $200 \mu \mathrm{l}$ of cell staining solution (Cell Biolabs) was added to each well followed by incubation for $10 \mathrm{~min}$ at room temperature. The stain was removed and the cells were washed four times with $500 \mu \mathrm{l}$ of deionized water. After allowing the cells to air dry for $25 \mathrm{~min}, 200 \mu \mathrm{l}$ of extraction solution (Cell Biolabs) was added to each well and placed on an orbital shaker for $10 \mathrm{~min}$. The absorbance of the extracted samples was measured at $560 \mathrm{~nm}$ by a Thermo Multiskan Spectrum plate reader. Results were corrected by subtracting the absorbance of the negative controls.

Reverse transcriptase-polymerase chain reaction (RT-PCR) analysis. Total RNA was extracted from FaDu cells, after treatment with $0,0.01,0.1$, or $1 \mu \mathrm{M}$ of colchicine for $72 \mathrm{~h}$, in TRIzol reagent (Gibco-BRI, Grand Island, NY, USA). An Omniscript Reverse Transcriptase Kit (Qiagen, Hilden, Germany) was used for reverse transcription of the RNA. Total RNA $(2 \mu \mathrm{g})$ was mixed with $20 \mu \mathrm{l}$ of the mixture: $2.0 \mu \mathrm{l}$ of $10 \times$ RT buffer, $2.0 \mu \mathrm{l}$ of dNTPs $(5 \mathrm{mM}$ each), $2.0 \mu \mathrm{l}$ of oligo-(dT) primer $(10 \mu \mathrm{M}), 1.0 \mu \mathrm{l}$ of RNase inhibitor $(10 \mathrm{U} / \mu \mathrm{l}), 2 \mathrm{U}$ of Omniscript reverse transcriptase and RNase-free water. Reverse transcription was performed and cDNA was synthesized. The synthesized cDNA was added to a mixture of $1 \mathrm{U}$ of Taq DNA polymerase (Roche Molecular Biochemicals) and specific primers and amplified using an MJ Research Minicycler (Bio-Rad Laboratories, Waltham, MA, USA). The following specific primers were used: Matrix metalloproteinase 2 (MMP2): forward: 5'-ACC TGG ATG CCG TCG TGG AC-3', reverse: 5'GTG GCA GCA CCA GGG CAG C-3'; MMP9: forward: 5'-TCT ATG GTC CTC GCC CTG AA-3', reverse: CAT CGT CCA CCG GAC TCA AA-3'; urokinase plasminogen activator $(u P A)$, forward: 5'-GCC ATC CCG GAC TAT ACA GA-3'; reverse: 5'-AGG CCA TTC TCT TCC TTG GT-3'; urokinase plasminogen activator receptor $(u P A R)$, forward: 5' -CTG GAG CTG GTG GAG AAA AG3', reverse: 5'-TGT TGC AGC ATT TCA GGA AG-3'. PCR was performed under the following conditions: denaturation for $3 \mathrm{~min}$ at $96^{\circ} \mathrm{C}$ followed by 30 cycles of $30 \mathrm{~s}$ at $94^{\circ} \mathrm{C}, 30 \mathrm{~s}$ at $55^{\circ} \mathrm{C}$ and 30 $\mathrm{s}$ at $72^{\circ} \mathrm{C}$, with extension for $5 \mathrm{~min}$ at $72^{\circ} \mathrm{C}$. PCR products were separated by electrophoresis in $1.5 \%$ agarose gels and detected under ethidium bromide staining and ultraviolet light (Bio-Rad).

uPA assay. FaDu cells (3,000 or 6,000 cells/well) were inoculated into 96-well plates in DMEM containing $10 \%$ FBS. Two sets of plates were prepared; uPA activity was measured on one plate and the other plate was used to measure cell growth. After overnight incubation, colchicine $(0,0.01,0.1,1 \mu \mathrm{M})$ was added to the wells and the plates were incubated for a further $24 \mathrm{~h}$. The cells were 

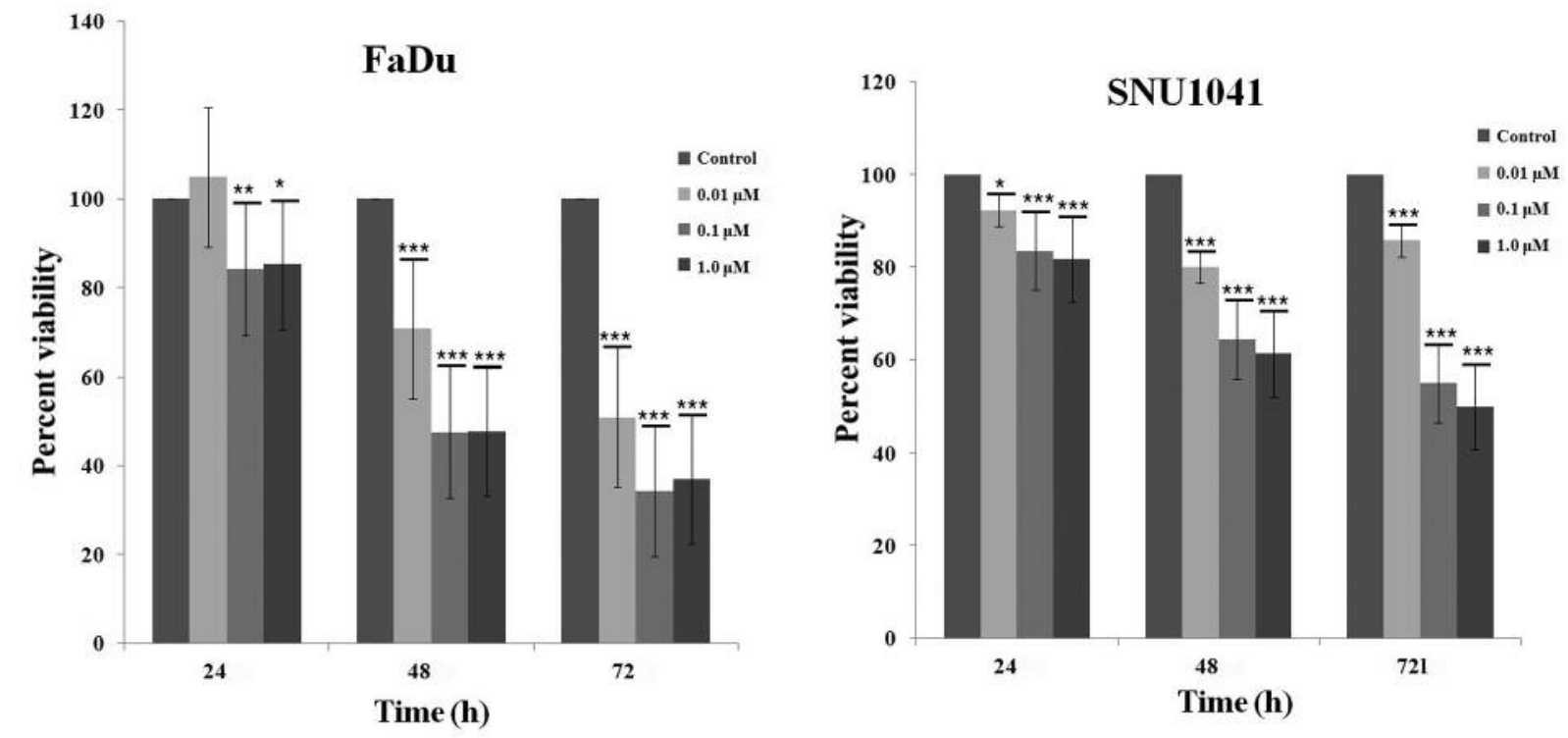

Figure 1. Effects of colchicine on the proliferation of hypopharyngeal cancer cells. Cell proliferation was estimated using the XTT assay. Colchicine significantly inhibited the proliferation of a hypopharyngeal cancer cell line. Values represent the means $\pm S D$ from three independent experiments. Significantly different at $* p<0.05, * * p<0.01, * * * p<0.001$ compared to the control group.

washed with DMEM without phenol red and placed in $200 \mu \mathrm{l}$ of reaction buffer containing $50 \%(\mathrm{v} / \mathrm{v}) 0.05 \mathrm{U} / \mathrm{ml}$ plasminogen in DMEM (without phenol red), 40\% (v/v) $50 \mathrm{mM}$ Tris-buffer (pH 8.2), and $10 \%$ (v/v) $2.25 \mathrm{mM}$ chromozyme PL (Sigma-Aldrich Co.) in $100 \mathrm{mM}$ glycine. The mixtures were incubated at $37^{\circ} \mathrm{C}$ in $5 \%$ $\mathrm{CO} 2$ for $3 \mathrm{~h}$ and the absorbance at $405 \mathrm{~nm}$ was measured in an automated spectrophotometric plate reader.

Zymography. MMP2 and MMP9 released from hypopharyngeal cancer cells, into the medium were assayed using gelatin zymography as described previously (6). FaDu cells were treated with $0,0.01$, 0.1 , or $1 \mu \mathrm{M}$ colchicine and incubated for an additional $24 \mathrm{~h}$. The supernatant $(100 \mu \mathrm{l})$ from each sample was mixed with $1 \mu \mathrm{l}$ of $100 \mathrm{mM} \mathrm{4-}$ aminophenylmercuric acetate, and the samples were activated for $1 \mathrm{~h}$ at $37^{\circ} \mathrm{C}$. Next, each sample was placed in sample buffer for $10 \mathrm{~min}$ and then electrophoresed in polyacrylamide gels, at $125 \mathrm{~V}$ for $120 \mathrm{~min}$ at $4^{\circ} \mathrm{C}$, using a Novex Xcell II system (Life Technologies, Carlsbad, CA, USA). The gels were incubated in renaturation buffer for $60 \mathrm{~min}$ at room temperature, followed by incubation for $18 \mathrm{~h}$ in $100 \mathrm{ml}$ of developing buffer at $37^{\circ} \mathrm{C}$ with light shaking. The gel was then stained for $3 \mathrm{~h}$ with Coomassie brilliant blue. After decolorization in $400 \mathrm{ml}$ of methanol, $100 \mathrm{ml}$ of acetic acid, and $500 \mathrm{ml}$ of distilled water, images were taken using an image analyzer.

Western blot analysis. After colchicine $(0,0.01,0.1,1 \mu \mathrm{M})$ treatment of cells for $24 \mathrm{~h}$, the cells washed with cold PBS. Cells were collected and lysed in lysis buffer. In order to ensure equal protein loading, the concentration of protein in each sample was determined by Bio-Rad Protein Assay. Samples (30 $\mu \mathrm{g}$ protein) were incubated at $100^{\circ} \mathrm{C}$ for $5 \mathrm{~min}$, separated on loaded $8 \%$ Tris-glycine gels by sodium dodecyl sulfate-polyacrylamide gel electrophoresis. After the proteins were run through the gel, they were transferred onto a nitrocellulose membrane by western blotting. The membranes were then blocked in 5\% skim milk for $1 \mathrm{~h}$ and then probed with primary antibodies from Cell Signaling Technology (Danvers, MA, USA) against focal adhesion kinase, SRC, paxillin, extracellular signal-regulated kinase, AKT, and $\beta$-actin at $4^{\circ} \mathrm{C}$ overnight. Afterwards, the corresponding secondary antibodies were then probed for $1 \mathrm{~h}$ at room temperature. Protein bands were visualized using an enhanced chemiluminescence detection system.

Animal study. Twenty 6-week-old female nude mice (BALB/c-nu) from Chungang Laboratory Animal Center (Seoul, South Korea), weighing around $20 \mathrm{~g}$, were used. After transportation, nude mice were maintained in the Central Animal Laboratory for at least 1 week. The feeding process was carried out by qualified staff using a syringe connected to a feeder. FaDu cells $\left(1 \times 10^{6}\right)$ re-suspended in PBS were subcutaneously inoculated into the left lower flank of each BALB/c-nu mouse. After 10 days, when tumors had reached approximately $5 \mathrm{~mm}$ in diameter, the mice were randomly divided into two groups ( $\mathrm{n}=5$ per group) and treatment was initiated. Each mouse in the experimental group was continuously fed with $0.1 \mathrm{mg}$ colchicine $/ \mathrm{kg}$ dissolved in PBS every 2 days for 14 days. Each mouse in the control group was fed PBS for 14 days. Tumors were measured with sliding calipers once every 3 days and the volume $(V)$ was calculated according to the formula $\mathrm{V}=A \times B^{2} \times 0.52$, where $\mathrm{A}$ is the largest superficial diameter and $\mathrm{B}$ is the smallest superficial diameter (7). The percentage tumor volume increase was calculated as $\left(V_{x} / V_{0}\right) \times 100$, where $V_{x}$ is the tumor volume at day $\mathrm{x}$ and $\mathrm{V} 0$ the baseline pretreatment tumor volume. All mice were euthanized and tumors were collected and weighed 15 days after the start of treatment. All tumors were immediately fixed in $24 \%$ formalin after sacrificing the mice. Hematoxylin and eosin staining and immunohistochemical staining for caspase-3 (Cell Signaling Technology) were performed on tumor tissues. This study was approved by the Department of Laboratory Animals, IACUC of the School of Medicine, The Catholic University of South Korea. 

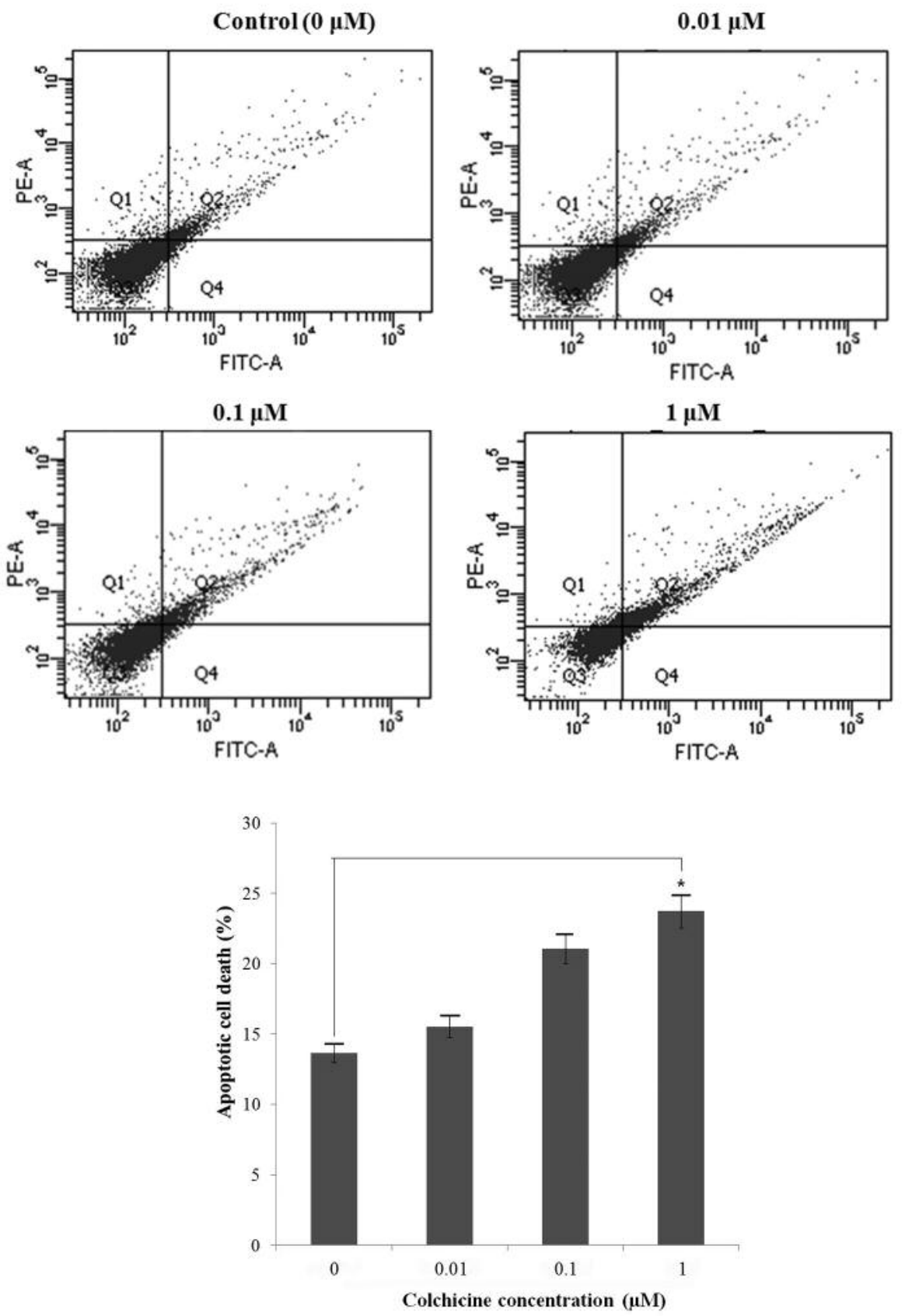

Figure 2. Flow cytometric detection of apoptotic cells. Early (Q2) and late (Q4) apoptosis were quantified. Colchicine increased apoptotic cell death in a dose-dependent manner. Values represent the means $\pm S D$ from three independent experiments. Significantly different at $* p<0.05$ compared the the control group.

Statistical analyses. Statistical evaluation of the data was performed using one-way analysis of variance (ANOVA) with a post-hoc Tukey's test. Results are expressed as means \pm SD from at least three independent experiments. A $p$-value of less than 0.05 was considered statistically significant. All statistical analyses were performed using SPSS for Windows software (ver. 18.0; SPSS Inc., Chicago, IL, USA).

\section{Results}

Colchicine induces cell death via apoptosis in a dose-dependent manner. We examined the cytotoxicity of colchicine by treating hypopharyngeal cancer cells with different concentrations $(0$, $0.01,0.1,1.0 \mu \mathrm{M}$ ) for 24,48 , and $72 \mathrm{~h}$ followed by XTT assay. 

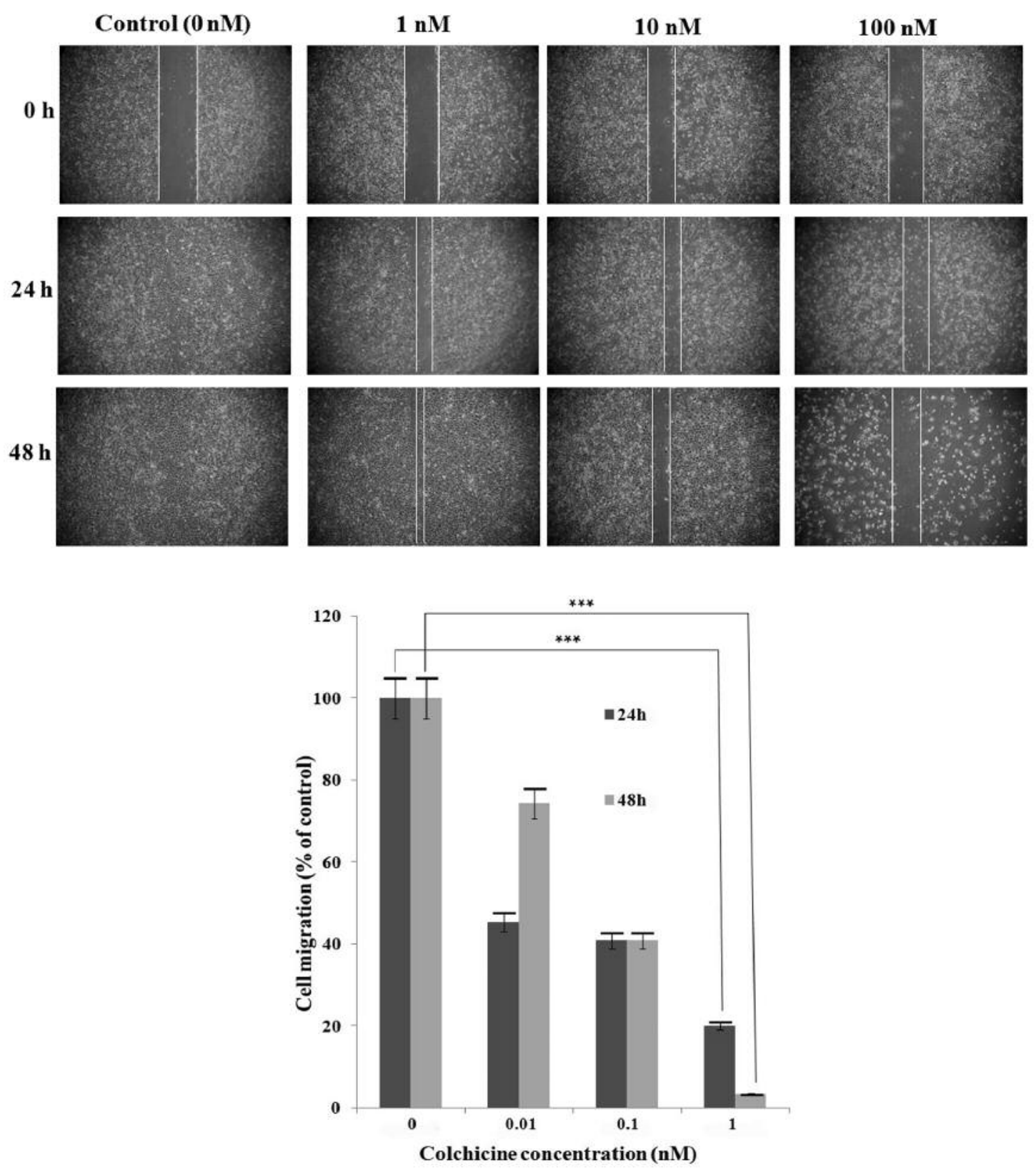

Figure 3. Wound healing assay. The migration of cells was quantified by measuring the distance between the edges of the wound (white lines). Colchicine inhibited cell motility in a dose-dependent manner. Values represent the means $\pm S D$ from three independent experiments. Significantly different at $* * * p<0.001$ compared to the control group.

Figure 1 shows that colchicine treatment had cytotoxic effects on both FaDu and SNU1041 cell lines in a dose- and timedependent manner. In order to determine whether colchicineinduced cell death occurred via apoptosis, we performed a FACS assay using annexin V/PI staining. Annexin V/PI-positive cells increased with colchicine treatment in the $\mathrm{FaDu}$ cell line in a dose-dependent manner (Figure 2).
Colchicine inhibits cell migration, invasion, and adhesion of human hypopharyngeal cancer cells. In order to investigate whether colchicine reduces tumor cell migration, wound healing and transwell chamber assays were performed. As shown in Figure 3, colchicine treatment significantly suppressed the migration of FaDu cells across the denuded zone and in the Transwell chamber. In the wound-healing 
A

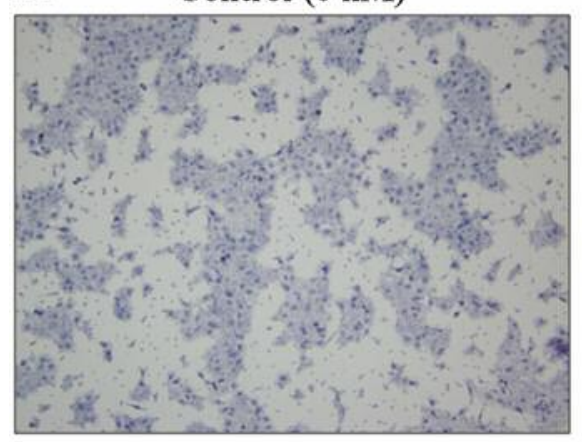

$10 \mathrm{nM}$

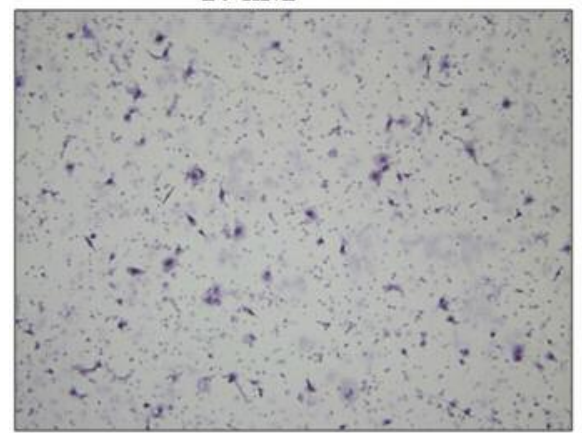

B Control $(0 \mathrm{nM})$

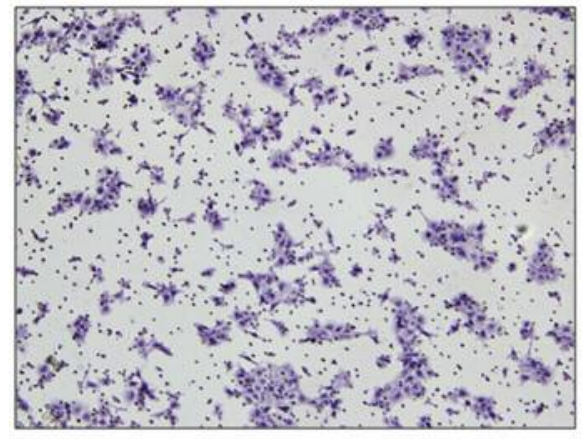

$10 \mathrm{nM}$

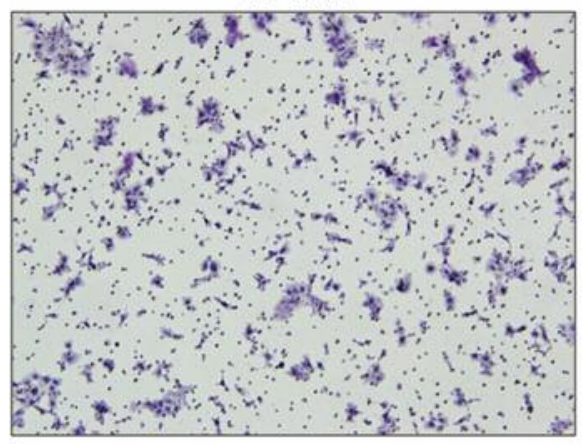

$1 \mathrm{nM}$

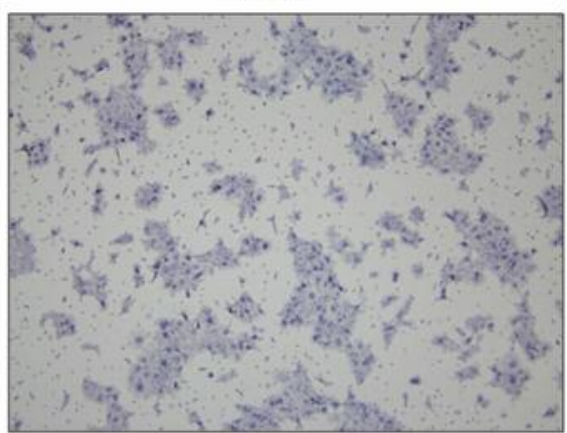

$100 \mathrm{nM}$

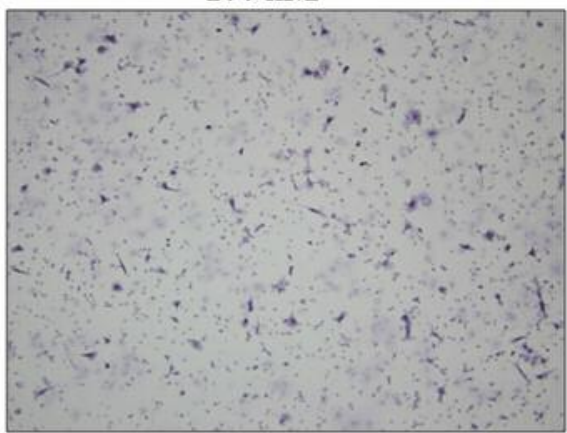

$1 \mathrm{nM}$

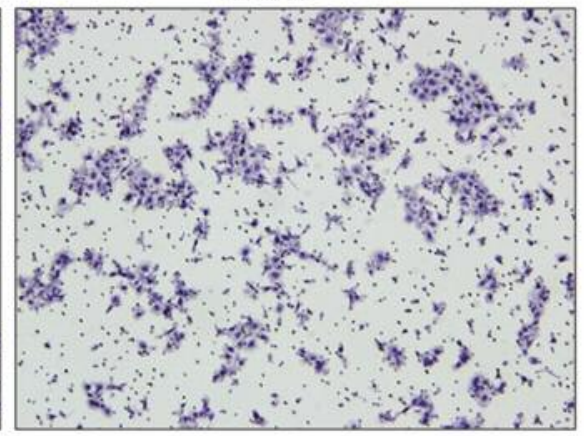

$100 \mathrm{nM}$

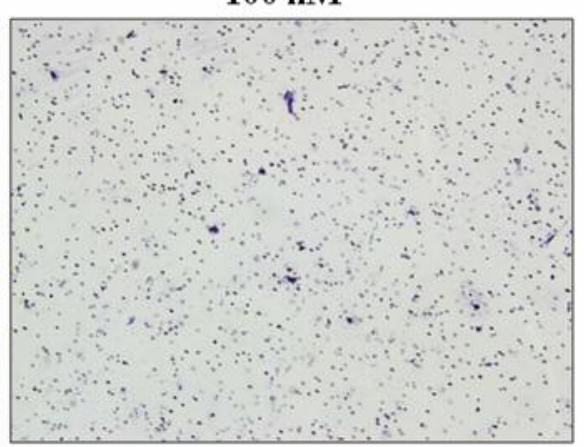

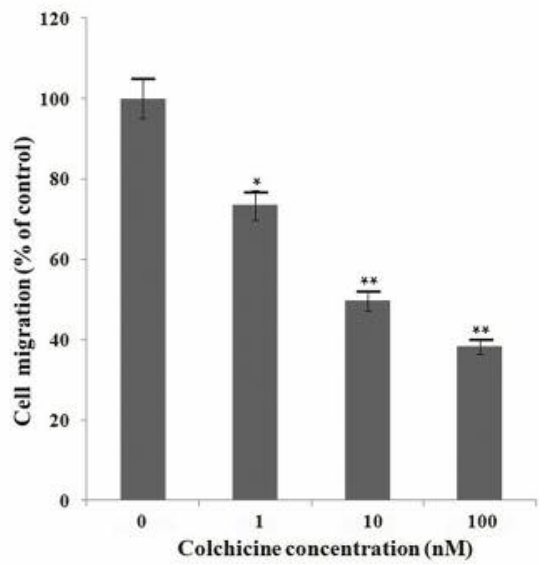

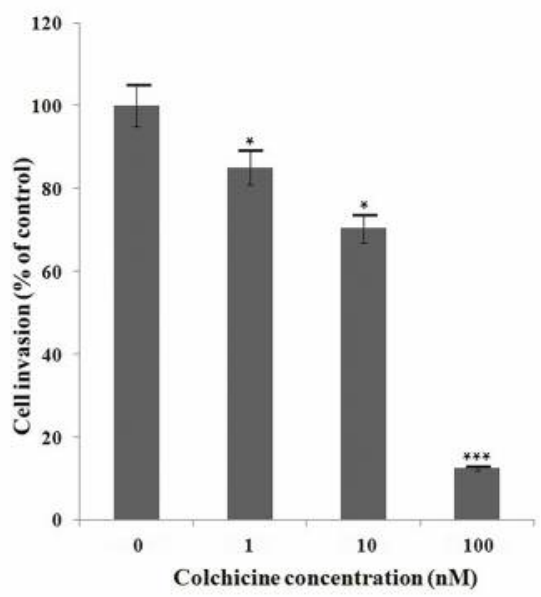

Figure 4. Continued 


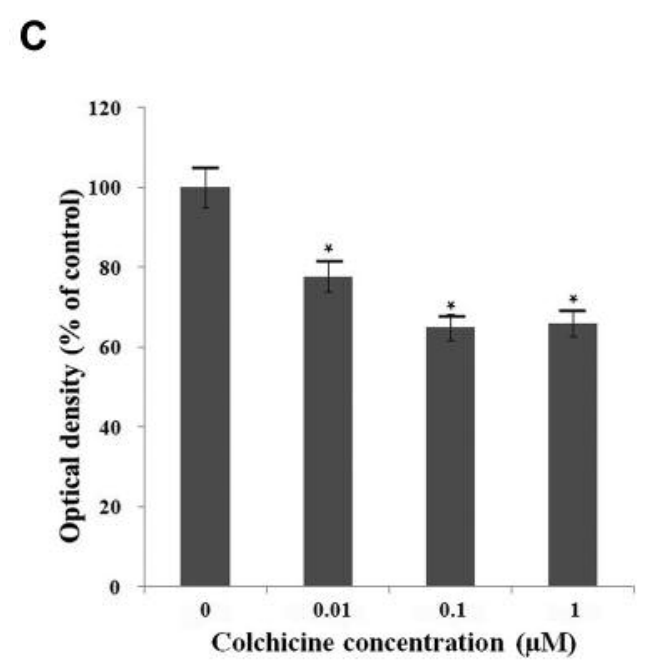

Figure 4. Effects of colchicine on cell migration, invasion, and adhesion. A: Migration was determined by Transwell assay. Colchicine significantly inhibited cell motility in a dose-dependent manner. Migratory cells were detected by hematoxylin staining and photographed. B: Effect of colchicine on the invasion of FaDu cells. Colchicine significantly inhibited the invasion of FaDu cells in a dose-dependent manner. C: Colchicine inhibited the adhesion of FaDu cells. Values represent the means $\pm S D$ from three independent experiments. Significantly different the control group at $* p<0.05 ; * * p<0.01, * * * p<0.001$.

assay, treatment with 10 and $100 \mathrm{nM}$ colchicine for $24 \mathrm{~h}$ inhibited cell migration by $58.6 \%$ and $80.0 \%$, respectively. Colchicine inhibited the motility of FaDu cells in a dosedependent manner. The migration assay, using a Transwell chamber, also confirmed that colchicine inhibited the migration of hypopharyngeal cancer cells in a dosedependent manner (Figure 4A).

Invasion assays were performed using Transwell chambers and collagen IV. Tumor invasion requires degradation of the basement membrane and extracellular matrix (ECM) and cytoplasmic extension. Transwell assays mimic this environment for tumor invasion. The attached cells in the lower section pass through the filter of the chamber, indicating invasive cells. As shown in Figure 4B, hematoxylin-stained cells were present on the undersurface of the membrane $24 \mathrm{~h}$ after incubation. Colchicine treatment significantly inhibited the number of invading cells in a dose-dependent manner.

Since cell-matrix interaction is important for cancer cell invasion, a cell-matrix adhesion assay was performed. The adhesion assay revealed that colchicine suppressed cell adhesion in FaDu cells (Figure 4C).

Colchicine inhibits cell invasion by reducing expression of MMP9 and UPA in human hypopharyngeal cancer cells. In order to understand the mechanism by which colchicine inhibits tumor invasion in vitro, RT-PCR for $M M P 2 / 9$ and $u P A / u P A R$ was performed. MMP9, $u P A$, and $u P A R$ mRNA expression significantly decreased after colchicine treatment for $78 \mathrm{~h}$ in a dose-dependent manner. However, the expression of MMP2 mRNA did not decrease (Figure 5). Gelatin zymography for MMP9, and an assay for uPA, were performed to evaluate their activity. MMP9 activity decreased after $24 \mathrm{~h}$ in the colchicine-treated group compared to the control group, while no MMP2 activity was detected (Figure 6A). In addition, colchicine inhibited uPA activity (Figure 6B). These findings suggest that colchicine inhibits cell invasion by reducing the transcription of $M M P 9$ and inhibiting $u P A$ activity. We examined the phosphorylation of AKT and ERK following treatment with increasing concentrations of colchicine $(0.01,0.1,1 \mu \mathrm{M})$ using western blot analysis. The results showed that ERK was not phosphorylated at a concentration of $0.1 \mu \mathrm{M}$ colchicine, but the phosphorylation of AKT increased (Figure 7).

Colchicine inhibits cell migration and adhesion by suppressing phosphorylation of the FAK/SRC complex and paxillin signaling in human hypopharyngeal cancer cells. FAK promotes cell migration and adhesion through complex formation with SRC and subsequent phosphorylation of paxillin, which is a cytoskeletal adaptor molecule $(8,9)$. In order to evaluate the effect of colchicine on cell migration and adhesion, we examined the phosphorylation of FAK, SRC, and paxillin. After colchicine treatment, we observed inhibition of FAK phosphorylation and a consistent reduction in the phosphorylation of SRC and paxillin (Figure 7).

Colchicine suppresses tumor growth by induction of caspase3-activated cell apoptosis in a nude mouse model. In order to determine whether colchicine has anticancer effects in vivo, we used BALB/C-nu nude mice and randomly divided them into a colchicine-treated group and a control group. All mice survived the experimental period. When the control and experimental groups were considered together, there was no significant difference in body weight during the treatment period between colchicine-treated and control mice. After 15 days, the tumor size in colchicine-treated mice was smaller than in the control group (Figure 8A). The tumor volume ratios in the colchicine-treated group increased at a slower rate than in the control group (Figure 8B).

Morphological study of cell shape changes was performed using tumor tissue sections. Tumor cells from the colchicinetreated group were more edematous and showed decreased mitosis compared to those of the control group. The tissue sections were then examined immunohistochemically to determine the expression of caspase-3. The colchicinetreated group showed intense staining in the cytoplasm, reflecting higher expression of caspase-3 compared with that in the control group (Figure 8C). 


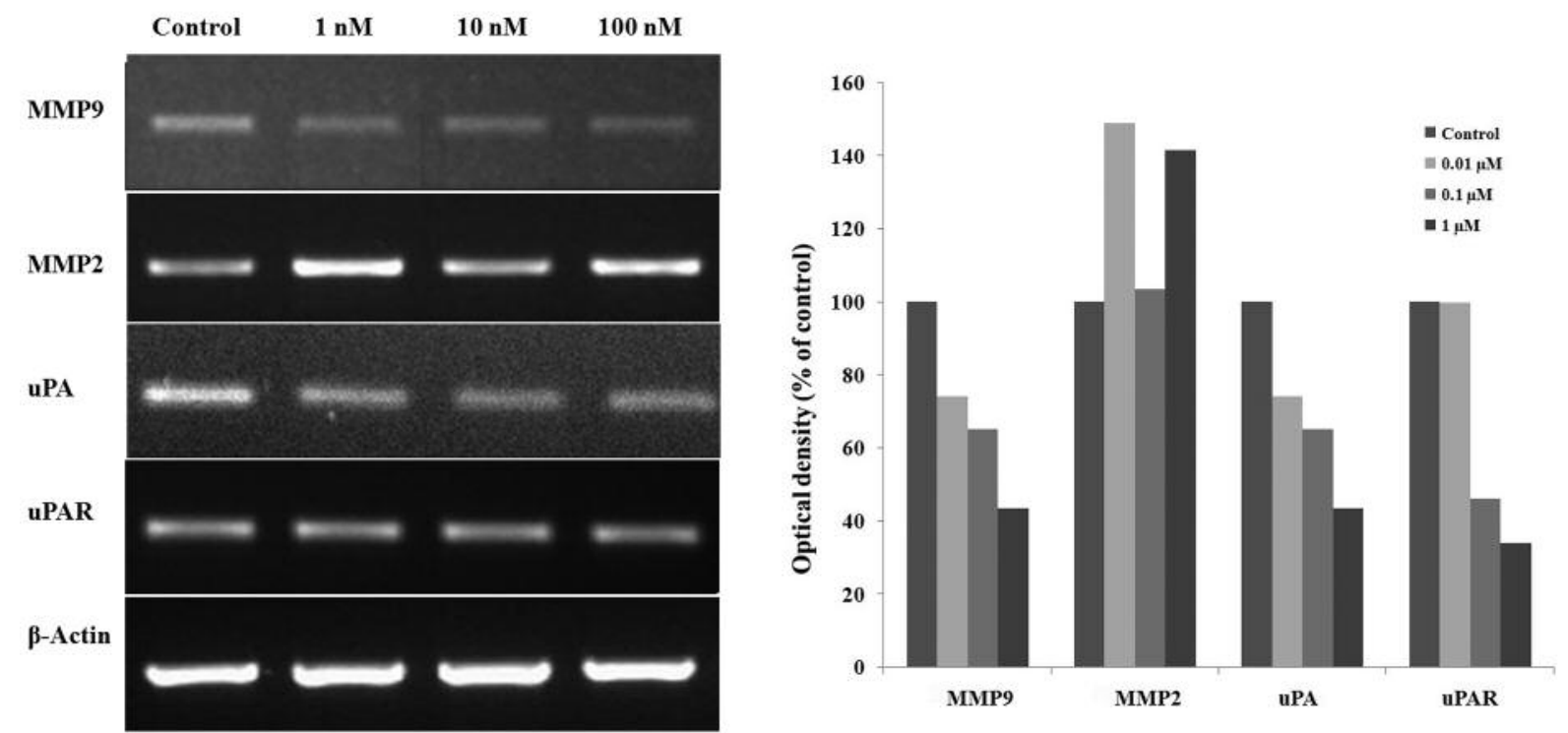

Figure 5. Effects of colchicine on the expression of matrix metalloproteinases (MMP) and the urokinase-type plasminogen activator (uPA) system determined using reverse transcription polymerase chain reaction. MMP9 mRNA expression decreased after $72 \mathrm{~h}$ in a dose-dependent manner, but the expression of MMP2 mRNA was not. Both uPA and UPAR mRNA expression decreased on treatment with colchicine.

\section{Discussion}

Colchicine arrests microtubule polymerization by binding to tubulin, which results in disruption of mitotic spindle formation, thereby suppressing cell division and leading to apoptosis (3). Colchicine also stabilizes the dynamics of mitotic spindle microtubules. Stabilization of microtubule dynamics correlates with blocking of the cell cycle at mitosis in sensitive tumor cells, ultimately resulting in cell death by apoptosis. Because cancer cells are more susceptible to being poisoned, colchicine as a mitotic inhibitor is more effective against cancer cells than normal cells.

Tumor cell metastasis includes several steps: detachment of the cancer cell from the primary tumor by changes in cellcell and cell-ECM adhesion, degradation of the ECM and basement membrane, invasion of tumor cells into the peripheral tissue, and finally intravasation into blood or lymphatic vessels and attachment at the target tissue (10). Among these essential steps, cell adhesion, migration and invasion are the main contributors to metastatic spread (11). In this study, we revealed that colchicine has significant anticancer effects on hypopharyngeal cancer cells by inhibiting cell migration, adhesion and invasion. Therefore, we believe that colchicine can play a role in blocking the development of the metastatic cascade.

It is clear that the ECM functions as a structural support for the cellular elements of cancer and also has a profound impact on the behavior of cancer cells, including their viability, proliferation, adhesion, and motility (12). Proteolysis of the ECM and basement membrane is an essential mechanism used by cancer cells for invasion and metastasis. In particular, uPA plays a major role in the adhesion, migration, invasion, and metastasis of cancer cells (13). uPA is initially secreted as an inactive pro-enzyme and binding of pro-uPA by uPAR allows the conversion of plasminogen to plasmin, which facilitates matrix degradation and indirectly activates MMPs (14). In addition, activation of $\mathrm{UPA}$ by $\mathrm{UPAR}$ results in the activation of the ERK pathway (also known as the mitogenic pathway), which leads to cell proliferation, migration and invasion (15). Increased uPA activity has been shown to facilitate remodeling of the surrounding tissues in a wide variety of cancer types. The expression of uPA is significantly up-regulated during cancer progression and is primarily confined to the tumor-associated stromal compartment (16). Previous studies showed that inhibition of the uPA system reduces invasion and metastasis in melanoma, colorectal cancer and papillary thyroid cancer by reducing the degradation of the ECM (17-19). In the current study, we found that colchicine reduced the secretion of uPA and down-regulated uPAR expression in hypopharyngeal cancer cells. It appears that inhibition of invasion by colchicine treatment in hypopharyngeal cancer cells is due to lower uPA activity.

MMPs are proteolytic enzymes involved in the degradation of the underlying basement membrane. They play a major role in ECM degradation and are crucial for 


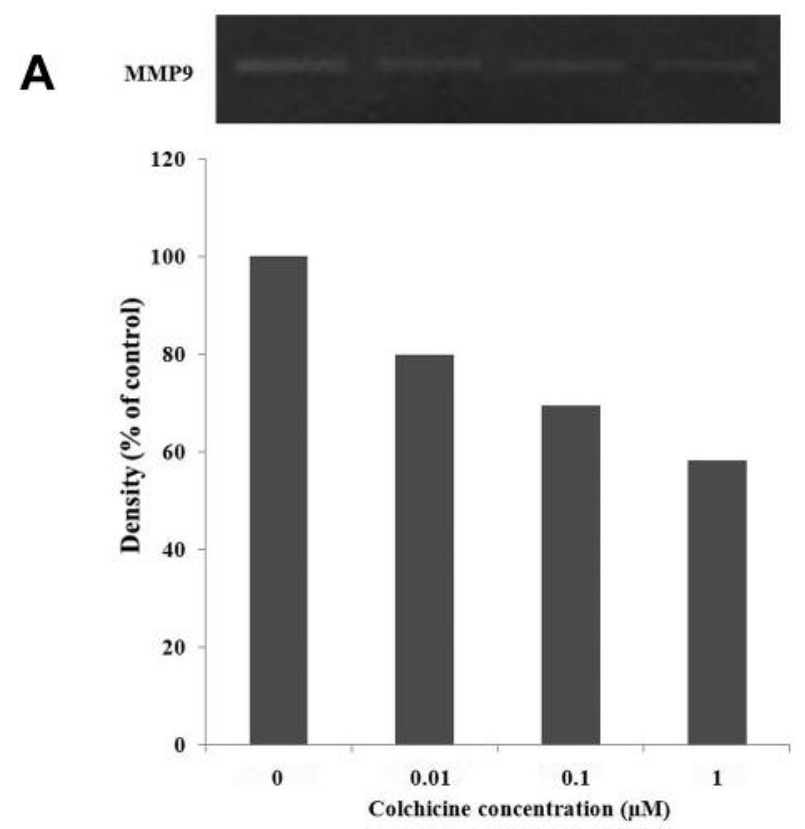

B

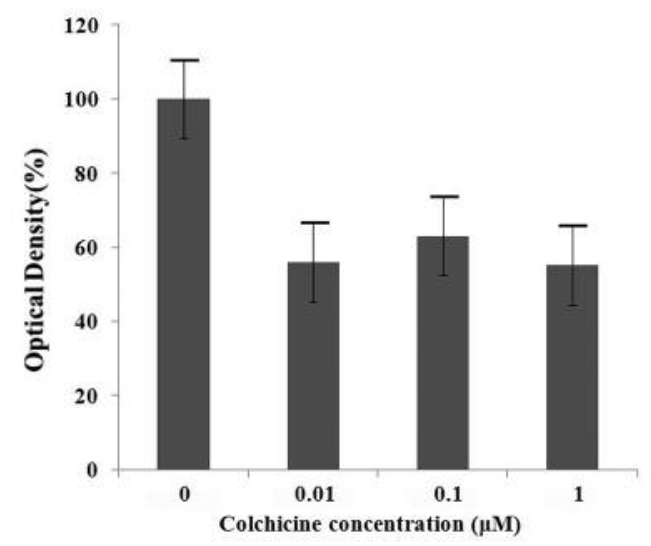

Figure 6. Assays for matrix metalloproteinase 9 (MMP9) and urokinase-type plasminogen activator (uPA). A: MMP9 activity was quantified by densitometric analysis using zymography. The activity of MMP9 decreased after colchicine treatment in a dose-dependent manner. B: uPA activity was attenuated after colchicine treatment in FaDu cells.

facilitating tumor migration and invasion during metastasis. Therefore, we investigated the contribution of MMPs to human hypopharyngeal cancer cell invasion. In many cancer types, an elevated plasma level of soluble MMPs positively correlated with a higher incidence of metastasis and this is considered a valuable prognostic factor (12). Of the MMPs, activated forms of MMP9 and MMP2 are thought to play an important role in basement membrane degradation because of their ability to cleave type-IV collagen. Therefore, we examined the effect of colchicine on the expression of MMP2 and MMP9 in hypopharyngeal cancer cells. In particular, previous studies reported that MMP9 expression is associated with distant metastasis and high recurrence rates in head and neck cancer $(20,21)$. RT-PCR revealed a marked decrease in the level of MMP9 mRNA, but not that of $M M P 2$ after colchicine treatment, and zymography confirmed the decrease in MMP9 activity. These data are consistent with previous studies in which the expression and activity of MMP9 were found to be weakly correlated with malignant or metastatic cancer phenotypes $(5,22)$.

Next, we investigated the downstream signaling pathway in the migration and invasion of hypopharyngeal cancer cells. Previous studies revealed that the MMP/uPA system is regulated through PI3K-AKT or ERK/p38 signaling (22, 23). We found colchicine treatment inhibited ERK

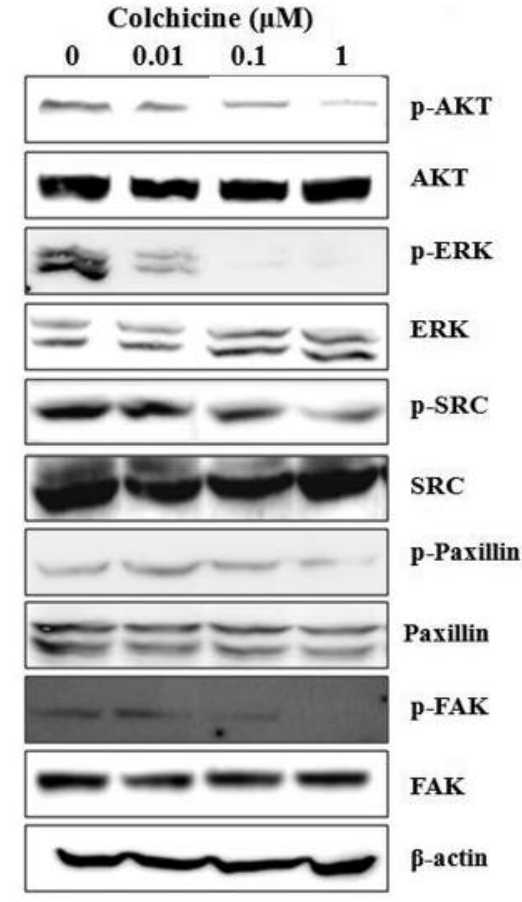

Figure 7. Western blotting of proteins in FaDu cells wih and without colchicine treatment. After 24 h treatment of FaDu cells with colchicine, the expression of phospho-extracellular signal-regulated kinase ( $p-E R K$ ) was significantly reduced. Expression of $p$-SRC, p-paxillin, and phospho-focal adhesion kinase ( $p$-FAK) were also observed. 

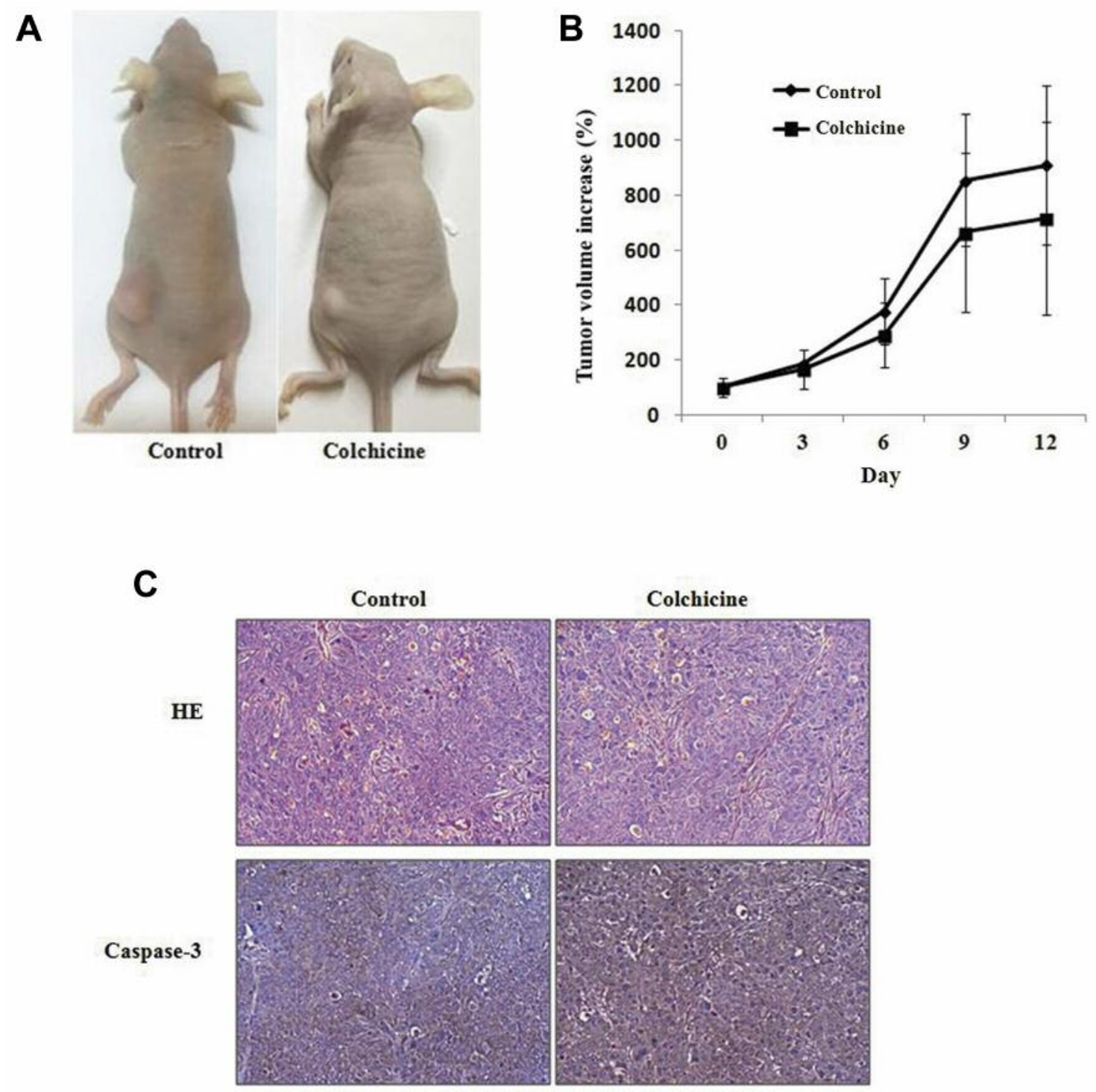

Figure 8. Effects of colchicine on tumor growth and apoptosis in a nude mouse model. A: Fifteen days after colchicine treatment, the tumor size was much smaller in colchicine-treated mice compared to control mice. B: Comparison of percentage tumor volume increase between colchicinetreated and control mice. The increase in tumor volume for colchicine-treated mice was lower than that for control mice after 15 days of treatment. $C$ : Tumor cells in the colchicine-treated group were edematous and exhibited decreased mitosis compared with the control group after hematoxylin and eosin (HE) staining (upper panel, $\times 200$ ). In order to determine whether the mechanism of cell death was apoptosis, immunohistochemical staining for caspase-3 was performed (lower panel, $\times 200$ ). Strong induction of caspase-3 was observed in the colchicine-treated group.

expression in a dose-dependent manner. Thus, our results revealed that colchicine reduces cancer cell invasiveness via the MMP9/uPA system, which is associated with ERK signaling. The ERK pathway is an important target for therapeutic interventions due to its integral role in regulating the proliferation, invasiveness, and survival of tumors. In addition, FAK is a non-receptor tyrosine kinase that is localized at focal adhesions. FAK protein expression is increased in the vast majority of invasive and metastatic tumors and is involved in many aspects of the metastatic process, including adhesion, migration, and invasion (24). FAK has been proposed as a target molecule for cancer therapy and several small-molecule FAK inhibitors have already been developed (25). Zhao et al. reviewed the FAK promotion of cell migration through complex formation with SRC, and subsequent phosphorylation of paxillin by 
the FAK/SRC complex (9). Paxillin is an intracellular scaffold protein that recruits structural or regulator proteins to modulate dynamic changes and cytoskeletal reorganization during cell migration and adhesion. Interestingly, FAK inhibition was shown to reduce MMP9 secretion in carcinoma cells (26). Therefore, the results of this study are consistent with these earlier studies, in that colchicine significantly inhibited cell migration and adhesion by suppressing the expression of the FAK/SRC complex and paxillin signaling.

Colchicine has not been clinically used in cancer treatment due to its potent toxicity at the doses required to elicit its anticancer effects. The oral colchicine dose used herein is higher than that used to treat gout in humans However, Lin et al. reported that clinically acceptable colchicine concentrations have anticancer effects on hepatocellular carcinomas (27). Moreover, colchicine at a concentration of $50 \mathrm{nM}$ has been shown to block almost all cells at mitosis (4). The peak plasma concentrations after oral administration, of 0.6 to $1 \mathrm{mg}$ colchicine, range from around 2 to $6 \mathrm{ng} / \mathrm{ml}$ (27). We orally administered $0.1 \mathrm{mg} / \mathrm{kg}$ colchicine every 2 days for 14 days in nude mice. All mice tolerated the colchicine. We found that colchicine effectively suppressed tumor growth without serious complications in the hypopharyngeal cancer model nude mice compared with the control group. Thus, we expect that the results of our study can be extended to the clinical setting with regard to safety and efficacy. The mechanism of colchicine-induced cell apoptosis includes the activation of caspase-3 (28). We confirmed this through immunohistochemical staining. In our in vivo study, strong induction of caspase-3 expression in tumors from colchicine-treated mice was evident compared with control mice. We did not examine whether normal cells and cancer cells exhibit differential sensitivity to colchicine. Therefore, further investigation is needed regarding whether colchicine has adverse effects on normal cells.

In conclusion, this study demonstrated that colchicine induced cell death by apoptosis and inhibited cell metastasis in hypopharyngeal cancer cell lines. Colchicine appears to inhibit the invasion and migration of hypopharyngeal cancer cells by reducing ECM degradation through down-regulation of $M M P 9$ and the uPA system. We also demonstrated the inhibition of tumor growth by colchicine at a clinicallytolerable dose in a nude mouse model. Therefore, our study suggests that colchicine has the potential to prevent the progression of hypopharyngeal cancer and may be useful as an additional treatment.

\section{Acknowledgements}

This research was supported by the St. Vincent's Hospital, Research Institute of Medical Science in 2014

\section{References}

1 Braakhuis BJ, Leemans CR and Visser O: Incidence and survival trends of head and neck squamous cell carcinoma in the Netherlands between 1989 and 2011. Oral Oncol 50: 670-675, 2014.

2 Risinger AL, Giles FJ and Mooberry SL: Microtubule dynamics as a target in oncology. Cancer Treat Rev 35: 255-261, 2009.

3 Sivakumar G: Colchicine semisynthetics: chemotherapeutics for cancer? Curr Med Chem 20: 892-898, 2013.

4 Bhattacharyya B, Panda D, Gupta S and Banerjee M: Antimitotic activity of colchicine and the structural basis for its interaction with tubulin. Med Res Rev 28: 155-183, 2008.

5 Ho YL, Li KC, Chao W, Chang YS and Huang GJ: Korean Red ginseng suppresses metastasis of human hepatoma SK-Hep1 cells by inhibiting matrix metalloproteinase-2/-9 and urokinase plasminogen activator. Evid Based Complement Alternat Med 2012: 965846, 2012.

6 Lim YC, Park HY, Hwang HS, Kang SU, Pyun JH, Lee MH, Choi EC and Kim CH: (-)-Epigallocatechin-3-gallate (EGCG) inhibits HGF-induced invasion and metastasis in hypopharyngeal carcinoma cells. Cancer Lett 271: 140-152, 2008.

7 Yuan ZP, Chen LJ, Fan LY, Tang MH, Yang GL, Yang HS, Du XB, Wang GQ, Yao WX, Zhao QM, Ye B, Wang R, Diao P, Zhang W, Wu HB, Zhao X and Wei YQ: Liposomal quercetin efficiently suppresses growth of solid tumors in murine models. Clin Cancer Res 12: 3193-3199, 2006.

8 Wu GS, Song YL, Yin ZQ, Guo JJ, Wang SP, Zhao WW, Chen XP, Zhang QW, Lu JJ and Wang YT: Ganoderiol A-enriched extract suppresses migration and adhesion of MDA-MB-231 cells by inhibiting FAK-SRC-paxillin cascade pathway. PLoS One 8: e76620, 2013.

9 Zhao J and Guan JL: Signal transduction by focal adhesion kinase in cancer. Cancer Metastasis Rev 28: 35-49, 2009.

10 Geiger TR and Peeper DS: Metastasis mechanisms. Biochim Biophys Acta 1796: 293-308, 2009.

11 Palmer TD, Ashby WJ, Lewis JD and Zijlstra A: Targeting tumor cell motility to prevent metastasis. Adv Drug Deliv Rev 63: 568581,2011

12 Deryugina EI and Quigley JP: Matrix metalloproteinases and tumor metastasis. Cancer Metastasis Rev 25: 9-34, 2006.

13 Mekkawy AH, Morris DL and Pourgholami MH: Urokinase plasminogen activator system as a potential target for cancer therapy. Future Oncol 5: 1487-1499, 2009.

14 Bauer TW, Liu W, Fan F, Camp ER, Yang A, Somcio RJ, Bucana CD, Callahan J, Parry GC, Evans DB, Boyd DD, Mazar AP and Ellis LM: Targeting of urokinase plasminogen activator receptor in human pancreatic carcinoma cells inhibits c-Met- and insulinlike growth factor-I receptor-mediated migration and invasion and orthotopic tumor growth in mice. Cancer Res 65: 77757781, 2005.

15 Aguirre Ghiso JA, Kovalski K and Ossowski L: Tumor dormancy induced by downregulation of urokinase receptor in human carcinoma involves integrin and MAPK signaling. J Cell Biol 147: 89-104, 1999.

16 Lund IK, Illemann M, Thurison T, Christensen IJ and HoyerHansen G: uPAR as anticancer target: evaluation of biomarker potential, histological localization and antibody-based therapy. Curr Drug Targets 12: 1744-1760, 2011. 
17 Nowicki TS, Kummer NT, Iacob C, Suslina N, Schaefer S, Schantz S, Shin E, Moscatello AL, Tiwari RK and Geliebter J: Inhibition of UPAR and uPA reduces invasion in papillary thyroid carcinoma cells. Laryngoscope 120: 1383-1390, 2010.

18 Shi H, Liu L, Liu L, Geng J, Zhou Y and Chen L: beta-Elemene inhibits the metastasis of $\mathrm{B} 16 \mathrm{~F} 10$ melanoma cells by downregulation of the expression of $\mathrm{UPA}, \mathrm{UPAR}, \mathrm{MMP} 2$ and MMP9. Melanoma Res 24: 99-107, 2014.

19 Zhuo J, Tan EH, Yan B, Tochhawng L, Jayapal M, Koh S, Tay HK, Maciver SK, Hooi SC, Salto-Tellez M, Kumar AP, Goh YC, Lim YC and Yap CT: Gelsolin induces colorectal tumor cell invasion via modulation of the urokinase-type plasminogen activator cascade. PLoS One 7: e43594, 2012.

20 Jeon YK, Lee BY, Kim JE, Lee SS and Kim CW: Molecular characterization of Epstein-Barr virus and oncoprotein expression in nasopharyngeal carcinoma in Korea. Head Neck 26: 573-583, 2004.

21 Pacheco MM, Kowalski LP, Nishimoto IN and Brentani MM: Differential expression of c-JUN and c-FOS mRNAs in squamous cell carcinoma of the head and neck: associations with uPA, gelatinase B and matrilysin mRNAs. Head Neck 24: 2432, 2002.

22 Chang JW, Kang SU, Shin YS, Kim KI, Seo SJ, Yang SS, Lee JS, Moon E, Lee K and Kim CH: Non-thermal atmospheric pressure plasma inhibits thyroid papillary cancer cell invasion via cytoskeletal modulation, altered MMP2/9/uPA activity. PLoS One 9: e92198, 2014.

23 Tong B, Lu D, Wei Z, Wang T, Xia Y and Dai Y: Gleditsioside $\mathrm{B}$, a triterpene saponin isolated from the anomalous fruits of Gleditsia sinensis Lam., abrogates bFGF-induced endothelial cell migration through preventing the activation of MMP2 and FAK via inhibiting ERK and PI3K/AKT signaling pathways. Vascul Pharmacol 58: 118-126, 2013.
24 Deramaudt TB, Dujardin D, Noulet F, Martin S, Vauchelles R, Takeda $\mathrm{K}$ and Ronde P: Altering FAK-paxillin interactions reduces adhesion, migration and invasion processes. PLoS One 9: e92059, 2014.

25 Zhao X and Guan JL: Focal adhesion kinase and its signaling pathways in cell migration and angiogenesis. Adv Drug Deliv Rev 63: 610-615, 2011.

26 Shibata K, Kikkawa F, Nawa A, Thant AA, Naruse K, Mizutani $\mathrm{S}$ and Hamaguchi M: Both focal adhesion kinase and c-RAS are required for the enhanced matrix metalloproteinase 9 secretion by fibronectin in ovarian cancer cells. Cancer Res 58: 900-903, 1998.

$27 \mathrm{Lin} \mathrm{ZY}, \mathrm{Wu} \mathrm{CC}$, Chuang $\mathrm{YH}$ and Chuang WL: Anticancer mechanisms of clinically acceptable colchicine concentrations on hepatocellular carcinoma. Life Sci 93: 323-328, 2013.

28 Chen XM, Liu J, Wang T and Shang J: Colchicine-induced apoptosis in human normal liver L-02 cells by mitochondrial mediated pathways. Toxicol In Vitro 26: 649-655, 2012.
Received April 12, 2017

Revised June 27, 2017

Accepted June 30, 2017 